\title{
ZEYTİN TARIMINDA ÇALIŞAN İŞÇİLERİN ÇALIŞMA DURUŞLARININ REBA YÖNTEMİ İLE ANALIZİ
}

\author{
Hüsre Gizem AKALP ${ }^{1 *}$, Uğur SAKLANGIÇ² , Sevil ÇIRAKOĞLU³
}

${ }^{1}$ Bursa Uludağ Üniversitesi, Teknik Bilimler MYO, Mülkiyet Koruma ve Güvenlik Bölümü ORCID No: http://orcid.org/0000-0001-7412-9112

2 Bursa Uludağ Üniversitesi, Teknik Bilimler MYO, Mülkiyet Koruma ve Güvenlik Bölümü ORCID No: http://orcid.org/0000-0003-3891-2948

3 Bursa Uludağ Üniversitesi, Teknik Bilimler MYO, Mülkiyet Koruma ve Güvenlik Bölümü ORCID No: http://orcid.org/0000-0001-6124-0954

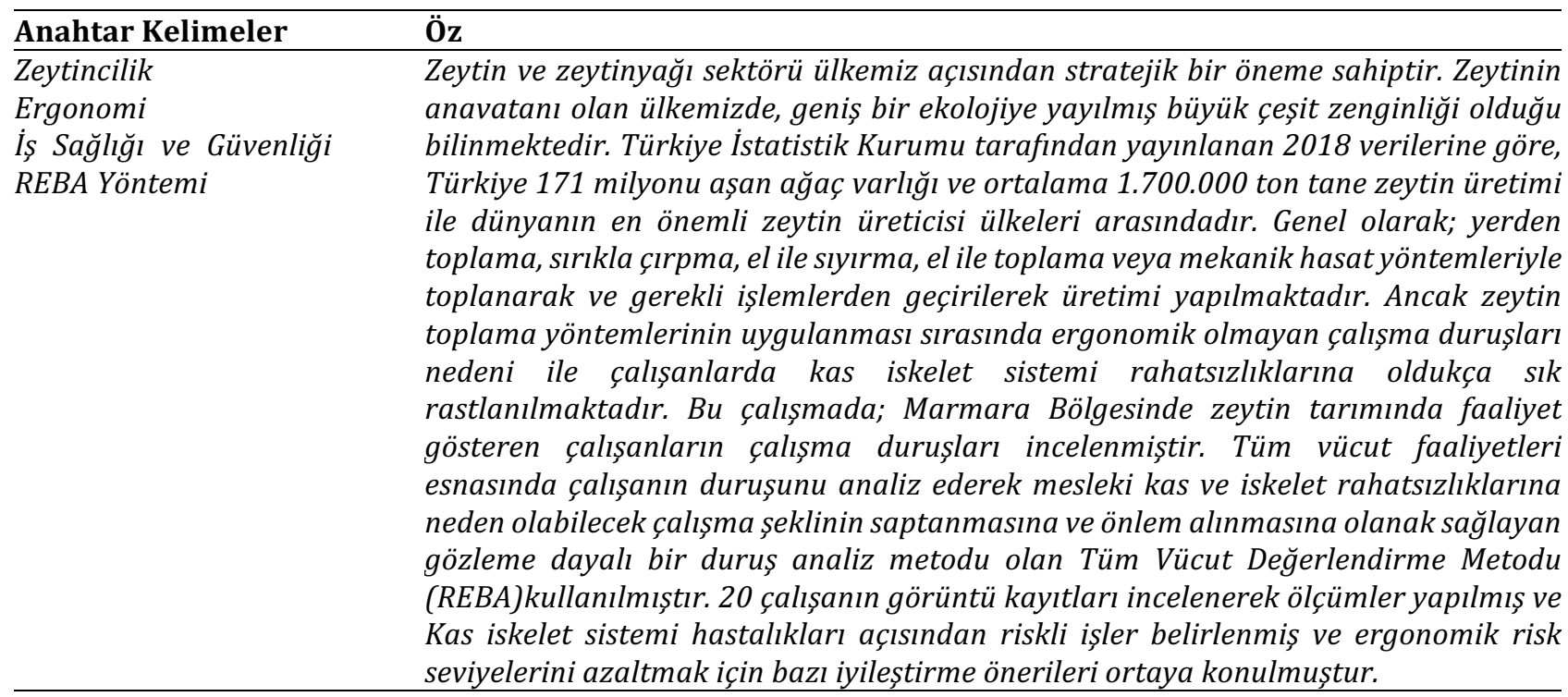

\section{ANALYSIS OF WORKING STOPS OF WORKERS WORKING IN OLIVE AGRICULTURE BY} REBA METHOD

\begin{tabular}{l} 
Keywords \\
\hline Olives \\
Ergonomics \\
Occupational Health \\
and Safety \\
REBA Method
\end{tabular}

Araștırma Makalesi

Başvuru Tarihi

Kabul Tarihi

\begin{abstract}
The olive and olive oil sector has a strategic importance for our country. In our country, which is the homeland of olives, it is known that there is a great variety of varieties spread over a wide ecology. According to 2018 data published by the Turkish Statistical Institute, Turkey is among the most important olive producing countries in the world, with over 171 million trees and an average olive production of 1,700,000 tons. Generally; It is produced by collecting from the ground, whisking with a pole, scraping by hand, collecting by hand or by mechanical harvesting methods and passing through the necessary processes. However, musculoskeletal disorders are quite common in workers due to non-ergonomic working postures during the application of olive picking methods. In this study; Working postures of employees operating in olive farming in the Marmara Region were examined. The Whole-Body Evaluation Method (REBA), an observation-based posture analysis method, was used to analyze the posture of the employee during all body activities, to determine the working style that may cause occupational musculoskeletal disorders and to take precautions. By examining the image records of 20 employees, measurements were made and risky jobs in terms of musculoskeletal diseases were determined and some improvement suggestions were put forward to reduce ergonomic risk levels.
\end{abstract}

$\begin{array}{lll} & \text { Research Article } & \\ : 02.07 .2021 & \text { Submission Date } & : 02.07 .2021 \\ 10.08 .2021 & \text { Accepted Date } & : 10.08 .2021\end{array}$




\section{Giriş}

Zeytin ve zeytinyağı yaklaşık 8000 yıl öncesinden bu yana dünyaya güzellik, sağlık ve lezzet pınarı olarak hizmet vermekte ve barışın sembolü olarak kabul edilmektedir. Zeytin ağacı, ağır büyüyen fakat uzun yaşayan, gövdesi çürümeye karşı çok dayanıklıdır. Zeytin ağacının meyvesi başlarda yeşil, daha sonra mor ve siyah renge dönüşür. Zeytin; su, protein, yağ, selüloz, fosfor, kükürt, kalsiyum, klor, demir, bakır, manganez A, $C$ ve $E$ vitaminlerinden meydana gelir. 100 gram zeytinde 224 kalori, 100 gr zeytinyağında 30 miligram E vitamini bulunmaktadır. Zeytin ağacı ortalama 700 ile 2000 yıla kadar yaşamaktadır. Killi, kireçli ve su geçirebilen topraklarda yetişmekte, engebeli ve yamaç, fakat llık rüzgârlı yerleri sevmektedir. Anavatanı Anadolu olan zeytin ağacı, Ege adalarından Yunanistan, İtalya, Fransa ve İspanya'ya kadar uzanmış ve buradan da Kuzey Afrika'ya geçmiştir. Dünya genelindeki zeytin yetiştiriciliğinin dağılımı incelendiğinde \% 90’lık bir kısmının Akdeniz havzası, geriye kalan kısmının ise Latin Amerika ülkelerinde yayıldığı gözlenmiştir (Sakar ve Ünver,2011:20).

Ülkemiz açısından da stratejik bir öneme sahip olan zeytin üretimi, Ege, Marmara ve Akdeniz bölgelerinin kıyı kesimlerinde yoğunlaşmaktadır.

Uluslararası Zeytin Konseyi verilerine göre zeytinyağı üretiminde 2018-2019 döneminde İspanya 1,6 milyon ton ile zeytinde olduğu gibi ilk sırada yer alırken onu 265 bin ton ile İtalya, 225 bin ton ile Yunanistan, 200 bin ton ile Fas ve 183 bin ton ile Türkiye izlemektedir. Dünya toplam zeytinyağı üretimi 3,1 milyon ton olarak gerçekleşirken İspanya yaklaşık \%51'ini tek başına yapmaktadır. Türkiye ise küresel zeytin üretiminin yaklaşı $\% 15,8$ 'sini gerçekleştirmektedir (Ekonomik Araştırmalar Şubesi, 2021).

Ülkemiz açısından bu kadar değerli olan bir ürünün üretilmesi aşamasında yer alan ürünün toplanması işlemi esnasında çalışanlarda uygun olmayan çalışma duruşları söz konusu olmaktadır. Ürünün toplanması aşaması iklim ve çalışma koşulları nedeniyle oldukça değişken bir ortamdır. Farklı sektörlerde teknolojik ilerlemeler kaydedilmesine rağmen, bu alanda iş yükü çok yüksek kalmaktadır.

Kas-iskelet sistemi bozuklukları, yüksek fiziksel iş yükleri nedeniyle zeytin toplama çalışanlarında yaygındır. İşin çoğu elle yapılması ve yoğun işgücü kullanımı gerektiren zeytin toplama işinde uygun olmayan çalışma duruşları, kas-iskelet sistemi rahatsızlıklarına neden olduğu gibi üretimin verimsizliğine de neden olmaktadır. $\mathrm{Bu}$ bozuklukların başlangıcıyla doğrudan ilişkili olarak not edilebilecek faktörler arasında tekrarlayan hareketler, zararlı duruşlar ve ağır yükler bulunmaktadır.

Kas iskelet sistemi rahatsızlıkları (KISR), özellikle endüstrileşmiş ülkelerde karşı karşıya kalınan yaygın sağlı sorunlarından biridir. KISR verimlilikte azalmaya, iş günü kayıplarına ve tazminat ödemelerinde artışa neden olmakla birlikte ülke ekonomilerini de olumsuz yönde etkilemektedir (Erciş ve ark., 2014).

Vücut eklemlerinin çalışma için en güvenli ve rahat duruş olan normal duruştan anlamlı düzeyde sapması, uygun olmayan çalışma duruşu olarak tanımlanmaktadır. Bu duruştan sapmalar, çalışanda yorgunluğa ve ağrıya neden olmanın yanı sıra çalışanı iş yapmaya ara vermek zorunda bırakmaktadır (Akay ve ark., 2003).

KİSR etiyolojisinde genel olarak çalışma ortamında karşılaşılan tekrarlayıcı hareketlerin sürekli yapılması, vücudun uygun olmayan pozisyonlarda uzun süre kalması ve titreşim maruziyeti ile ortaya çıkan birikimli travmaların etkisi söz konusudur (Bilir, 2011; Kaya ve Akalp, 2017). İşe bağlı KISR kişinin gösterdiği fiziksel çaba ile ilişkili olup, dünyanın her tarafında karşılaşılan yaygın sağlık problemlerinden biridir (İçağasıoğlu ve ark., 2015).

KİSR kaslarda, sinirlerde, tendonlarda, bağ dokularda, birleșme noktalarında ve disklerde meydana gelen yaralanma ve bozukluklar sonucu oluşan hastalıklardır (Akay ve ark., 2003). Bu hastalıklar eğilme, tutma, bükme ve uzanma gibi hareketler nedeniyle oluşmaktadır (Kahya, 2020). Bu hareketler günlük yaşam içerisinde süreklilik olmadan yapıldıklarında ciddi zararları olmamakla birlikte, iş yaşamında sürekli tekrar durumu söz konusu olduğunda, güç gerektirdiğinde ve hızlı yapıldığında oldukça zararlı hale gelmektedirler. KİSR, ayrıca, statik çalışma pozisyonları, sıcaklık derecesi düşük ortamlarda çalışma, aşırı iş yükü, titreşim, sıkışma, çalışma ortamının ergonomik prensiplere göre tasarlanmaması gibi risk faktörleri nedeniyle ortaya çıkmaktadır (Kaya, 2015; Özel ve Çetik, 2010).

Çalışma hayatında KİSR; bel, boyun ve üst ekstremite (el bileği, el, dirsek ve omuz) hastalıkları olarak sinıflandırılmaktadır. Bel ve sırt ağrıları, kas zorlanması ve incinmesi, boyun tutulması, boyun fitığı, bel fitığı, karpal tünel sendromu, gergin boyun sendromu ve kas kuvveti dengesizlikleri işten kaynaklanan başlıca kas iskelet sistemi rahatsızlıklarıdır. KİSR'da en sık tutulan bölgeler bel, boyun, eller, el bilekleri, 
dirsekler ve omuzlardır (Esen, Fı̆̆lalı, 2013'den aktaran Atıcı ve ark.; Kaya ve Özok, 2017).

KISR önleyebilmenin en önemli yolu bireylerin karşı karşıya kaldığı ergonomik tehlikelerin belirlenmesi ve bu kapsamda ergonomik risk değerlendirmelerinin yapılmasıdır. Ergonomik iyileştirmelerin ve düzenlemelerin nasıl yapılması gerektiği, ergonomik risk değerlendirmeleri sonucu belirlenmelidir. Literatür incelendiğinde, ergonomik riskleri değerlendirmek için birbirinden farklı özellikte pek çok yöntem bulunduğu görülmektedir. $\mathrm{Bu}$ yöntemler, çalışırken çalışanın duruşunu değerlendirmek ya da yaptığı işin unsurlarını ele almak üzere tasarlanmışlardır. Ergonomik riskler değerlendirilirken yapılan işe uygun yöntemlerin seçilmesi gerekmektedir.

$\mathrm{Bu}$ çalışma kapsamında, zeytin tarımında çalışanlara yönelik KİSR risk düzeylerinin Hızlı Tüm Vücudu Değerlendirme (Rapid Entire Body Assessment, REBA) yöntemi ile tespit edilmesi amaçlanmıştır. Gözleme dayalı yöntemlerden olan REBA, çalışma pozisyonlarıyla ilişkili risklerin ölçülmesinde ve çalışma duruşu esnasında çalışanın bütün vücudunun değerlendirilmesinde kullanılan yaygın bir araçtır.

Zeytin işletmelerinde çalışanların ergonomik risk değerlendirmeleri açısından ilgili literatür incelendiğinde, farklı yöntemlerle gerçekleştirilmiş bir iki çalışma haricinde REBA yönteminin uygulandığı bir çalışma ile karşılaşılmamıştır.

Bu kapsamda Marmara Bölgesinde zeytin hasadı yapan yirmi (20) çalışanın görüntü kayıtları incelenerek ölçümler yapılmış ve kas iskelet sistemi hastalıkları açısından yaptıkları riskli işler belirlenmiş, ergonomik risk seviyelerini azaltmak için bazı iyileştirme önerileri ortaya konulmuştur.

\section{Bilimsel Yazın Taraması}

Hignett ve McAtamney tarafından geliştirildikten sonra kullanışlılığı fark edilen REBA yöntemi ile yapılmıș birçok çalışma bulunmaktadır.

REBA yöntemini incelemek açısından literatür taraması yapıldığında birçok farklı sektörde ve uygulamada tercih edilen bir yöntem olduğu görülmektedir. Bu kapsamda REBA yöntemi kullanılarak yapılan bazı çalışmalara yer verilmiștir.

Sa ve arkadaşları 2006 yılında, diş hekimliği çalışmalarında duruş zorluklarının değerlendirilmesi amacı ile RULA (Rapid Upper Limb Assessment) ve REBA yöntemlerinin karşılaştırılmasını yapmışlardır. Paraiba Federal
Üniversitesinde diş hekimliği öğrencilerinin duruş zorluklarını iş pozisyonlarını araştırarak ve fotoğraflayarak, analiz etmişlerdir. Bu şekilde 39 durus pozisyonu analiz edilmiş ve sonuçlarda RULA yöntemi ile hesaplamalarında duruş skoru 5.5, REBA skoru ise 7,1 olarak değerlendirmişlerdir. Bulunan risk skoru değerlendirilmiş ve orta derecede riskler için küçük değişiklikler yapılmasına ihtiyaç duyulmuştur. Sonuç olarak diş hekimleri işlerinin büyük bir bölümünde vücutlarının üst kısmını hareket ettirdikleri için RULA yöntemi ile daha sağlıklı analizlere ulaşılacağı görüşüne varmışlardır (Sa ve ark., 2006).

2011 yilında Scott Rud tarafından, bir şirkette yüksekliği dikkate alarak kargo kutularının güncel kaldırma teknikleri ile ergonomik risk analizi REBA ve RULA yöntemleri ile gerçekleşmiştir. Yüksekte bulunan kargo kutuları ve bu kutuların uygunsuz kaldırılmaları nedeniyle gerçeklesen sakatlanma oranları sanayi ortalaması ile karşılaştırılmış ve daha yüksek olduğu görülmüştür. $\mathrm{Bu}$ araştırma sonucunda, kargo kutularının kaldırılmasından dolayı oluşan risk faktörlerinin azaltılması gerektiği ve çalışanları eğitmek için kullanılan kişisel koruyucu donanım ve idari kontrollerin belirlenmesi gerektiği ortaya çlkmıştır (Rud.,2011).

Tarım, ormancılık faaliyetlerinde REBA uygulamaları incelendiğinde, Das ve Gangopadhyay'in kas-iskelet bozukluklarını değerlendirmek için patates yetiştiricilerinde REBA'yı uyguladığı görülmektedir. Bu çalışmanın sonuçlarına göre, çalışanlarda en çok etkilenen vücut bölgelerinden birinin bel bölgesi olduğu belirlenmiştir (Das ve Gangopadhyay,2015).

Das ve arkadaşları benzer bir çalışmayı 10-16 yaş aralığındaki 120 patates yetiştiricisini inceleyerek REBA ve OWAS yöntemi ile gerçekleștirmiş ve aynı şekilde bel bölgesinin en çok etkilenen (\%98) bölge olduğunu belirlemişlerdir (Das ve ark., 2013).

Yöntem ayrıca Silver ve arkadaşları tarafından domates yetiştiriciliğinde çalışan göçmen tarım işçilerine yönelik uygulanmış, bel ve sırt bölgesinin en fazla etkilenen bölge olduğu belirlenmiștir (Silver ve ark., 2014).

Riemer ve arkadaşları tarafından da güneybatı İsrail'de bulunan iki çiftlikteki seralarda biber ve domatesin kafeslenme ve hasat aşamalarına çalışan işçilerde yöntemin uygulanması sonucu, domates yetiştiriciliği için el ile kaldırılan kutuların ağırlığının en fazla 12 kg olmasının tarımda manuel iş süreçlerinde karşı karşıya kalınan kas-iskelet yaralanmalarını azaltabileceği belirtilmiştir (Riemer ve ark., 2016). 
Deros ve arkadaşları tarafından da palmiye yağı üreticilerinde bu yöntemin kullanıldığı görülmektedir. Çalıșmanın sonuçlarına göre, çalışanların \%81,4'ü elle taşıma görevlerini gerçekleștirmek için sağlık ve güvenlik bilincine sahiptir ve doğru yöntemlerden haberdardır. Ancak \%87,1'i bel ağrısı ve \%94,3'ü sırt ağrısı yaşamaktadır (Deros ve ark., 2016).

$\mathrm{Bu}$ uygulamaların haricinde REBA yöntemi, Pal tarafından 2018 yılında pirinç yetiştiriciliğinde değerlendirilmiştir. Pirinç ekimi işinde çalışan kadın yetiștiricilerin postural stresini ve kasiskelet bozukluğu (MSD) prevalansını değerlendirmeyi amaçlayan çalışmada postural stres, OVAKO Çalışma Duruşları Analiz Sistemi (OWAS), Hızlı Tüm Vücut Değerlendirmesi (REBA), Hızlı Üst Ekstremite Değerlendirmesi (RULA) ve Hızlı Maruz Kalma Kontrol Listesi (QEC) yöntemleriyle ve ayrıca ağırlık merkezi ölçülerek değerlendirilip karşılaştırılmıştır (Pal,2018).

Ülkemizde Adana ve Mersin bölgesinde seracılık sektöründe çalışanların karşılaştığı ergonomik risklerin değerlendirilmesi amacı ile 08/09/2014 - 08/12/2014 tarihleri arasında iç ve diș mekân süs bitkisi yetiștiren sekiz seradan ve domates yetiştirilen iki seradan, 30/03/201503/04/2015 tarihleri arasinda da muz yetiştirilen yedi seradan toplanan verilerle 27 adet REBA analizi gerçekleştirilmiş ve çalışanların gerekli sağlık güvenlik bilincine sahip olmadıkları ve REBA skorları incelemelerinde önlem alınması gereken risk skorlarına sahip oldukları belirlenmiştir (Kır, 2015).

Enez ve Nalbantoğlu tarafından yapılan bir çalışmada, Ankara Orman Bölge Müdürlüğüne Bağlı Beypazarı Orman İşletme Müdürlüğü Beypazarı, Eğriova ve Kapaklı Orman ișletme Şefliklerinde 2013 yılı üretim faaliyetleri sırasında gerçekleştirilmiştir. Çalışan üretim postaları dikkate alınarak ormancılık faaliyeti gösteren 58 üretim çalışanı incelenerek kayıt altına alınmıştır. Sonuç olarak ormancılıkta üretim ișlerinin REBA "ya göre "orta" düzeyde olduğu değerlendirilmiştir (Enez ve Nalbantoğlu, 2015).

Tavşanlı Organize Sanayi Bölgesinde yer alan bir firmada, çalışanlarda zorlanmaya neden olan duruşların REBA yöntemi ile ergonomik analizini inceleyen Atıcı ve arkadaşları, işletmede gerçekleștirilen kablo demetleme konveyör hattında montaj işlemi açısından, ergonomik olmayan çalışma pozisyonu belirlemişlerdir. $\mathrm{Bu}$ çalışmada REBA skorunu 8 bulmuşlardır (Atıcı ve ark., 2015).
Denizli ilinde faaliyet gösteren büyük ölçekli bir firmanın üretim hattında çalışanların çalışma duruşlarının değerlendirilerek fiziksel iş yüklerinin belirlenmesi amacı ile uygulanan REBA yönteminde, işletme içerisinde 31 işin risk seviyesi orta ve daha yüksek bulunmuștur (Polat ve ark., 2017).

Aygün ve arkadaşları, tarafından narenciye hasadının ergonomik açıdan incelenmesi amacı ile yapılan bir çalışmada, özellikle ağaç dalları üzerinde yapılan kesme ve toplama işi ile narenciye dolu küfelerin sırtta taşınması, çalışanı en çok zorlayan işler olarak tespit edilmiştir (Aygün ve ark., 2018).

Erdemir ve Erdem, 2019 yılında, REBA yöntemi ile bir döküm atölyesindeki çalışma duruşlarının dijital insan modelleme tabanl ergonomik analizini yapmışlardır. REBA skoru 10 olarak oldukça yüksek seviyede bir sonuç vermiştir (Erdemir ve Erdem, 2020).

REBA ile ilgili bilimsel makaleleri ve bibliyografikleri inceleyen ve "Web of ScienceCore Colection" veri tabanının kullanıldığı Gutierrez ve arkadaşlarının yaptığı çalışmada REBA yönteminin kullanımı, bilgi, ülke, yıl ve dergi sektörleri açısından incelenmiştir. En çok imalat sektöründe (\%24.18) kullanılan yöntem, "Tarım, Ormancılık ve Balıkçılık" sektöründe $\% 21,98$ ve diğer faaliyetler kapsamında da $\% 19,78$ olarak belirlenmiștir (Gutierrez ve ark., 2020). Neredeyse her zaman diğer yöntemlerle birlikte kullanılabilen REBA, uygunsuz duruşları belirlemek açısından faydalı bir yöntemdir.

\section{Yöntem}

Bu çalışma, üniversite etik kurulunun 28.05.2021 tarih ve E-92662996-044-15435 sayılı onayı ile, Marmara Bölgesi, Bursa Gemlik ilçesinde zeytin hasadı yapan yirmi (20) çalışan ile gerçekleștirilmiştir. Çalışanların yaptıkları işler gözlenmiş, video kayıtları ve fotoğraflanmış görüntü kayıtları incelenerek REBA yöntemi ile ölçümler yapılmış ve kas iskelet sistemi hastalıkları açısından yaptıkları riskli işler belirlenmiştir. Beraberinde, ergonomik risk seviyelerini azaltmak için bazı iyileştirme önerileri ortaya konulmuştur. Yapılan çalışma ile ergonomik açıdan uygun olmayan çalışma pozisyonlarını belirlemek ve zeytin tarımında çalışanlar için ergonomik bir çalışma ortamı yaratmak amaçlanmıştır. Analiz yapılırken, zeytin toplama esnasındaki ortak işler göz önünde bulundurularak, tekrarlanmış duruş analizinden kaçınılmıştır. Çalışan öncelikle konu hakkında bilgilendirilerek ve normalde nasıl çalışıyor ise o şekilde çalıştığından emin olunarak araştırmacılar tarafından video kayıt ve fotoğraflamaları yapılmıştır. 20 çalışandan elde 
edilen skorlar araştırmacılar tarafından hazırlanan excel programında değerlendirilerek hesaplanmış ve sonuçlar tablo 2 de gösterilmiştir.

Hizmet sektörlerinde hatalı duruș pozisyonlarını belirleyebilmek amacı ile Hignett ve McAtamney (1998, 2000) tarafından geliştirilen REBA yöntemi özellikle elle yapılan taşıma, kaldırma işlemlerindeki riskleri hesaplamak için kullanışlı bir araçtır. Yöntem geliştirilirken ergonomist ve fizyoterapistlerden oluşan bir ekip tarafından 600'den fazla vücut duruşu örneği toplanarak kodlanmıştır. Ekibin amacı, statik ve dinamik duruşa bağlı yüklenme faktörleri ve yerçekimi destekli üst ekstremite pozisyonu kavramlarını birleştiren bir yöntem oluşturmaktır (Hignett ve McAtamney, 2000). REBA yöntemiyle hem dinamik hareketler hem de sabit durușlar analiz edilebilmektedir.

Bu yöntemde, analiz edilmek istenilen duruş veya hareketin neden olduğu toplam risk, sayısal olarak ifade edilebilir. Riski sayısal olarak ifade edebilmenin en büyük avantajı, analiz edilen duruştaki özel hareket ve duruşların ayrı ayrı meydana getirecekleri risk ve tehlikeli durumlarını belirtmektir. Belirtilen her bir hareket veya durus üst ve alt vücut için açllara ayrılarak toplam skor, boyun, gövde ve alt ve üst uzuvların pozisyonlarının kombinasyonu ile hesaplanır. Yönteme dahil edilen diğer faktörler ise kaldırılacak yükün kolaylık derecesi, yük üzerindeki kavrama şekli, hareketin ne sıklıkta yapıldığı, hareket sırasında vücudun sabit durması veya hareket ettiğinde aynı zamanda dönme, bükülme olup olmadığıdır (Kocabaş, 2009; Sue ve McAtamney, 2000).

Yöntem, çalışma duruşlarını sayısal olarak elde etmeyi sağlamaktadır. REBA yöntemi, bir çalışma duruşu esnasında boyunda, gövdede, üst kollarda, bacaklarda, alt kollarda ve bileklerde ortaya çıkan eklem bükme hareketi (fleksiyon) ve eklem germe hareketine (ekstansiyon) bağlı çalışanın maruz kaldığı yüklere karşılık olarak 1 ile 15 arasında değişen bir skor ile belirlenmektedir. Bu sayede analiz edilmek istenen duruş ve hareket sayısal olarak elde edilir. Bu yönteme göre, bir çalışma duruşunun REBA skoru belirlenirken öncelikle vücut kısımları, A ve B Grubu olmak üzere ikiye ayrılır. A grubunu oluşturan uzuvlar gövde, boyun ve bacaklardır. B grubu ise üst kollar, alt kollar ve bileklerden meydana gelmektedir. REBA yöntemine göre sağ ve sol uzuvlar aynı zaman için değerlendirilmektedir.

"REBA durus puanlama tablolarına göre; gövde, boyun ve bacaklar A gurubunu, üst kol, alt kol ve bilek B gurubunu oluşturur. A grubunda belirlenen bu değere yük/kavrama skoru eklenir.
Yük/kavrama tablosuna göre verilecek değer, <5 $\mathrm{kg}$ ise 0 puan, $5-10 \mathrm{~kg}$ arası ise 1 puan, $>10 \mathrm{~kg}$ ise 2 puan, ani veya hızl kuvvet artışı var ise +1 puan şeklindedir. $B$ grubunda belirlenen değere kavrama skoru eklenir. Kavrama skoru 0 ile 3 arasındadır. Bu değerler, iyi bir tutma ve orta derecede kavrama gücü var ise 0 puan, el tutuşu uygun fakat ideal değil veya vücudun başka bir bölgesi ile kavrama uygun ise 1 puan, el tutuşu uygun değil fakat mümkün ise 2 puan, zor ve güvenli olmayan tutuş var ve tutma kolu yok ise veya vücudun başka bir bölgesini kullanarak uygun olmayan tutus ise 3 puan şeklindedir" (Inyang, 2012: 79; Stanton ve ark., 2009).

Elde edilen A ve B skorlarının C tablosunda birleştirilmesi ile $\mathrm{C}$ skoru belirlenir. Belirlenen $\mathrm{C}$ skoruna aktivite skor değeri eklenerek REBA skoru elde edilir. Aktivite skor değeri, bir veya birden fazla vücut bölgesi sabit ise +1 puan, kısa aralıklarla tekrar edilen işler var ise (yürüme hariç) +1 puan, yapılan iş duruşta hızlı ve büyük değişiklilere neden oluyorsa veya sabit olmayan zeminde çalışılıyorsa +1 puan eklenmesi şeklinde hesaplanır (Sue ve McAtamney, 2000: 204). REBA duruşları için excel tablosu, Fotoğraf 1 de gösterilmektedir.

REBA'nın bir iş örneklemesine dayanması, çalışma sırasındaki postürlerin sergilenme sıklığının tespit edilmesinin sağlanması, zeytin işinde çalışanların kas iskelet sisteminin işle ilgili risk faktörlerinin zorlanma analizinde kullanılması, verilerin kolaylıkla gözlem yoluyla elde edilmesi ve kâğıt kalem kullanılarak analiz edilebilmesi, ayrıca uygulamanın kolay bir yöntem oluşu nedeni ile zeytin tarımında çalışanlar için kullanılabilirliğini göstermektedir.

\section{Fotoğraf 1. REBA Duruşları için Excel Tablosu}

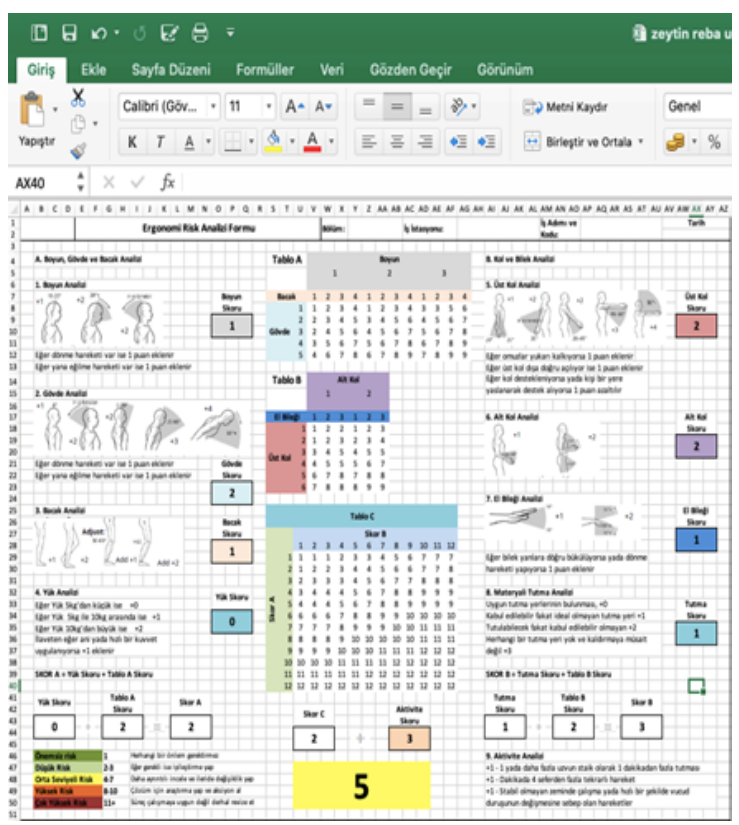



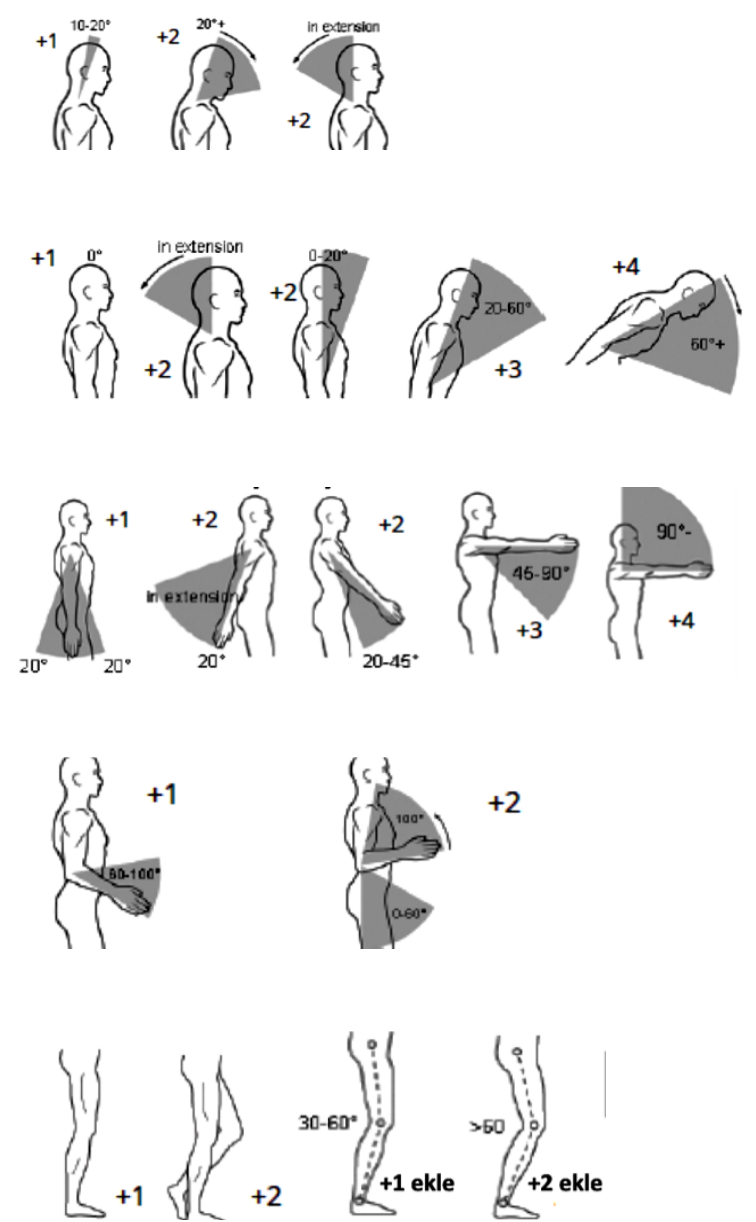

Şekil 1. REBA Yönteminde Kullanılan Kol, Bilek, Boyun Ve Gövdenin Duruş Pozisyonuna Ait Tanımlamaları (Aygün ve ark., 2018).

Sonuçta ortaya çıan REBA Skoru, Tablo 1'de verilen Risk Eylem Karar tablosundan kontrol edilerek, risk için alınacak önlemin aciliyet durumu belirlenir (Karwowski ve Marras, 1999: 8-7).

Tablo 1. Risk Eylem Karar Tablosu

\begin{tabular}{|c|c|c|c|}
\hline Derece & REBA Skoru & Risk Seviyesi & Önlem \\
\hline 0 & 1 & inmal Edilebilir & Gerekli Değil \\
\hline 1 & $2-3$ & Düşük & Gerekli olabilir \\
\hline 2 & $4-7$ & Orta & Gerekli \\
\hline 3 & $8-10$ & Yüksek & Kısa zaman içerisinde Gerekli \\
\hline 4 & $11-15$ & Çok Yüksek & Hemen Gerekli \\
\hline
\end{tabular}

\section{Bulgular}

Zeytin hasadının doğru zamanda ve doğru metot seçilerek yapılması hem zeytin ve zeytinyağının miktarını ve kalitesini belirlediği gibi hem de ağacın sağlı̆̆ını etkileyerek sonraki yıllardaki verimini de belirlemektedir. Zeytin toplama işlemi sofralık ve yağlık olarak iki farklı şekilde gerçekleşmektedir. Elle ve el tırmıkları ile yapılan zeytin toplama işinde zeytin kabuğunun zarar görmemesi ve etli kısmının da ezilmemesi gerekir. Toplama işleminde meydana gelebilecek olumsuz bir durum zeytinin piyasa değerini düşürür.

Ağaçtan elle veya tırmık yardımı ile toplanan zeytinler çuvallar içerisinde değil, zeytin naklinde kullanılacak plastik kasalarda taşınmaktadır. Fakat zeytin çalışanının ergonomik olmayan duruşlarda çalışması, kas iskelet sistemi rahatsızlıkları ve çalışan maliyeti yönünden de negatif etkiler oluşturmaktadır. Elle toplamada günlük toplanan miktar, çalışan başına 65 - 70 kg'a düşmektedir.

Marmara Bölgesi, Bursa Gemlik ilçesinde zeytin hasadı yapan yirmi (20) çalışan ile gerçekleştirilen bu çalışmada, zeytin hasadı yapan kişilerin fotoğraflarından bazıları örnek olması amacı ile aşağıda fotoğraf 2 ve 3 'de verilmiştir. Çalışanlar zeytin toplama işi esnasında uzanma, dönme ve eğilme hareketleri yapmaktadırlar. Özellikle ağaç dalları üzerinde yapılan kesme ve toplama işi çalışanların zorlanmalarına neden olmaktadır.

\section{Fotoğraf 2. Zeytin Toplama Çalıșanı Örnek Duruşlar-1}
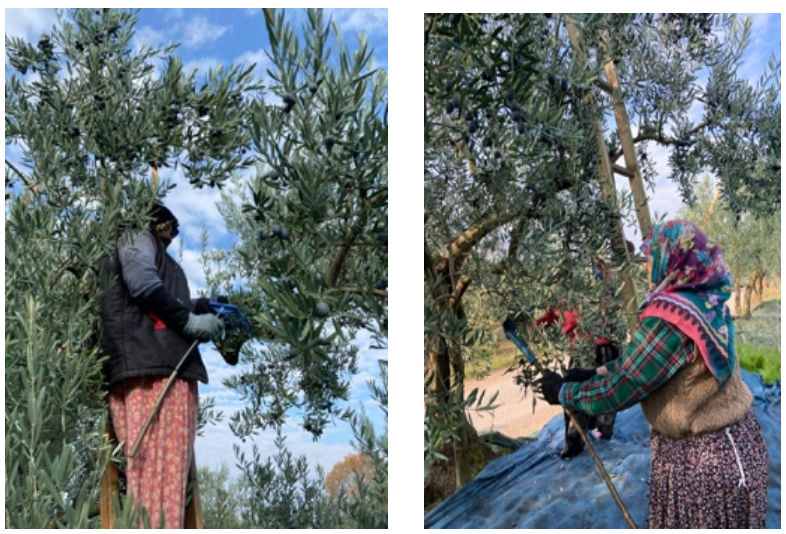

\section{Fotoğraf 3. Zeytin Toplama Çalışanı Örnek Duruşlar-2}
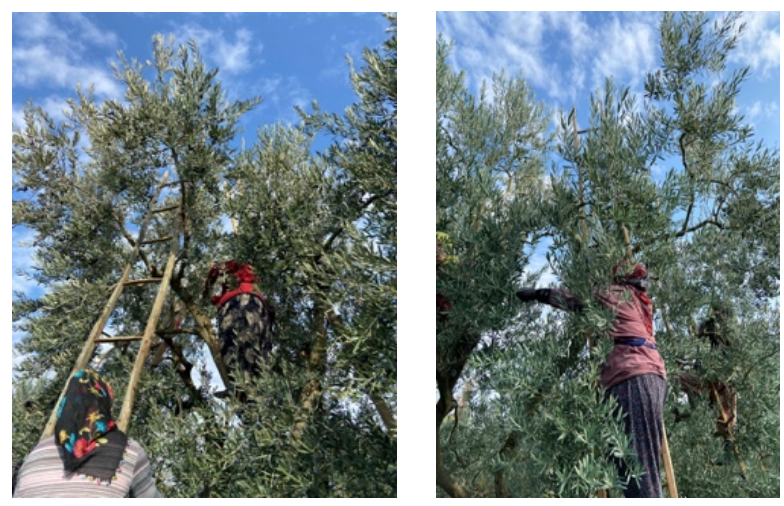

Tablo 2 de, gözlemlenen zeytin işçilerinin REBA skorları verilmektedir. 
Tablo 2. İşçilerin REBA Skorları

\begin{tabular}{|c|c|c|c|c|c|c|c|c|c|c|c|c|c|c|c|c|c|c|c|c|c|}
\hline \multirow[t]{2}{*}{ DURUŞLAR } & \multicolumn{21}{|c|}{ KișíLER } \\
\hline & 1 & 2 & 3 & 4 & 5 & 6 & 7 & & 8 & 9 & 10 & 11 & 12 & 13 & 14 & 15 & 16 & 17 & 18 & 19 & 20 \\
\hline Boyun & 2 & 3 & 3 & 3 & 3 & 1 & 3 & & 2 & 2 & 2 & 3 & 3 & 3 & 3 & 2 & 2 & 3 & 3 & 3 & 2 \\
\hline Bacak & 1 & 2 & 1 & 2 & 2 & 1 & 2 & & 1 & 1 & 1 & 1 & 2 & 2 & 2 & 1 & 1 & 2 & 2 & 1 & 1 \\
\hline Göyde & 2 & 3 & 4 & 3 & 3 & 2 & 3 & & 2 & 2 & 2 & 4 & 3 & 3 & 3 & 2 & 2 & 3 & 3 & 4 & 2 \\
\hline $\begin{array}{l}\text { Yük/ } \\
\text { Kuvvet }\end{array}$ & 0 & 0 & 0 & 0 & 0 & 0 & 0 & & 0 & 0 & 0 & 0 & 0 & 0 & 0 & 0 & 0 & 0 & 0 & 0 & 0 \\
\hline A SKORU & 3 & 6 & 6 & 6 & 6 & 2 & 6 & & 3 & 3 & 3 & 6 & 6 & 6 & 6 & 3 & 3 & 6 & 6 & 6 & 3 \\
\hline Alt Kol & 2 & 2 & 2 & 2 & 2 & 2 & 2 & & 2 & 2 & 2 & 2 & 2 & 2 & 2 & 2 & 2 & 2 & 2 & 2 & 2 \\
\hline Bilek & 2 & 2 & 2 & 2 & 2 & 1 & 2 & & 2 & $2:$ & 2 & 2 & 2 & 2 & 2 & 2 & 2 & 2 & 2 & 2 & 2 \\
\hline Ost Kol & 2 & 2 & 3 & 2 & 2 & 2 & 2 & & 2 & 2 & 2 & 3 & 2 & 2 & 2 & 2 & 2 & 2 & 2 & 3 & 2 \\
\hline Kavrama & 1 & 1 & 2 & 2 & 1 & 1 & 1 & & 1 & 1 & 1 & 2 & 1 & 2 & 2 & 1 & 1 & 1 & 1 & 2 & 1 \\
\hline B SKORU & 4 & 4 & 7 & 5 & 4 & 3 & 4 & & 4 . & 4 . & 4 & 7 & 4 & 5 & 5 & 4 & 4 & 4 & 4 & 7 & 4 \\
\hline CSKORU & 3 & 7 & 9 & 8 & 7 & 2 & 7 & & 3 & 3 & 3 & 9 & 7 & 8 & 8 & 3 & 3 & 7 & 7 & 9 & 3 \\
\hline $\begin{array}{l}\text { Aktivite } \\
\text { Skoru }\end{array}$ & 3 & 3 & 3 & 3 & 3 & 3 & 3 & & 3 & 3 & 3 & 3 & 3 & 3 & 3 & 3 & 3 & 3 & 3 & 3 & 3 \\
\hline $\begin{array}{l}\text { REBA } \\
\text { SKORU }\end{array}$ & 6 & 10 & 12 & 11 & 10 & 5 & & & 6 & 6 & 6 & 12 & 10 & 11 & 11 & 6 & 6 & 10 & 10 & 12 & 6 \\
\hline $\begin{array}{l}\text { RiSK } \\
\text { SEVIYESI }\end{array}$ & 0 & $\mathrm{Y}$ & ÇY & Cr & $\mathrm{Y}$ & 0 & r & & 0 & 0 & 0 & $C Y$ & $\mathrm{Y}$ & CY & ÇY & 0 & 0 & $\mathrm{Y}$ & $\mathrm{Y}$ & ç & 0 \\
\hline ONLEM & G & A & $\mathrm{H}$ & H & A & c & 19 & & G & G & G & H & A & H & H & G & G & A & A & H & G \\
\hline
\end{tabular}

Tablo 3. REBA Değer Ortalamaları

\begin{tabular}{|c|c|}
\hline & $\begin{array}{c}\text { REBA ANALi̇zi ORTALAMA } \\
\text { DEĞER }\end{array}$ \\
\hline Boyun & 2,9 \\
\hline Bacak & 1,45 \\
\hline Gövde & 2,75 \\
\hline Yük/kuvvet & 0 \\
\hline A skoru & 4,75 \\
\hline Alt kol & 2 \\
\hline Bilek & 1,95 \\
\hline Üst kol & 2,15 \\
\hline Kavrama & 1,3 \\
\hline B skoru & 4,55 \\
\hline C skoru & 5,8 \\
\hline Aktivite skoru & 3 \\
\hline Reba skoru & 8,8 \\
\hline Risk seviyesi & Yüksek \\
\hline Önlem & Acil önlem \\
\hline & \\
\hline & 4 \\
\hline
\end{tabular}

Tablo 3 incelendiğinde, A grubu parametreler içerisinde, boyun ve gövde parametresinin özellikle bazı duruşlarda yüksek değer aldığı dikkati çekmektedir. Yapılan gözlemlerde, çalışanların merdiven üzerinden eğilme burulma yani doğrudan belden hareket yapmalarının bu duruma sebep olduğu söylenilebilir.

B grubu parametrelerinin değerlendirilmesi ve gözlenmesi sonucu ise çalışanların budama makasları gibi antropometrik özellikleri yeterli olmayan ekipman kullanmasının bu parametreler üzerinde etken olduğu söylenebilir.

\section{Tartışma}

$\mathrm{Bu}$ çalışma çerçevesinde toplam 20 zeytin çalışanının zeytin toplama faaliyetleri gözlemlenerek kayıt altına alınmış ve çalışmalarına ait ergonomik değerlendirmelerde bulunulmuştur. Farklı koşullar altında gerçekleştirilen zeytin tarım işlerinde çalışanların çalışma duruşlarına yönelik durușlarının tüm vücut olarak değerlendirildiği postürleri sergileme sıklığı, iş örneklemesine dayanan REBA yöntemi kullanılarak değerlendirilmiștir. Bu yönteme göre zeytin tarım işçilerinin karşı karşıya kaldıkları risklerin "orta", "yüksek" ve "çok yüksek" düzeyde olduğu sonucuna ulaşılmıştır.

Araştırma sonuçlarına göre; özellikle ağaç dalları üzerinde yapılan kesme ve toplama işi, çalışanı en çok zorlayan işler olarak belirlenmiştir. Zeytin hasat ve sonrasında yapılan taşıma işi, çalışanların bedensel yükünü artırmaktadır. Bu tarz hasat ve taşıma işlemlerinin uzun dönemde kas iskelet sistemi rahatsızlıklarına yol açabileceği öngörülmektedir.

Genellikle taşınabilir merdivenler, bazı durumlarda da plastik kasaların üzerine çıkarak, düzgün olmayan zeminde çalışmak, plastik kasanın içe doğru kırılması, merdiven ile yapılacak çalışmalarda merdiven açısından alınması gereken önlemlerin alınmamış olması veya çalıșanın termal konfor şartlarının da etkisi ile baş dönmesi gibi sebeplerle geriye doğru düşmesi de yaralanma riski oluşturacağı için mutlaka dikkat edilmesi gereken konulardır.

Gerek yapılan gözlemler gerekse ölçümlerden elde edilen sonuçlar, zeytin tarım işlerinin ergonomik olmayan koşullarda gerçekleştiğini göstermektedir. İşin yapılışı esnasında çalışanların, eldiven haricinde herhangi bir KKD kullanmaması ve yağmur, soğuk vb. iklimsel olumsuz şartlara rağmen çalışmaya devam etmeleri de dikkate alınması gereken ergonomik riskler olarak değerlendirilmelidir.

REBA risk seviyesini düşürmek için, çalışanın antropometrik ölçülerine göre riskli bölgedeki zorlanmayı azaltacak alet, makineler tercih edilmeli, yapılan işe yönelik ve daha verimli çalışmayı sağlayacak şekilde iş ve metot etüdü çalışmaları yapılmalıdır.

REBA risk seviyesinin düşürülemediği durumlarda çalışan, fizik tedavi uzmanı tarafından belirli periyotlar içerisinde muayene edilmeli ve kas iskelet sistemini rahatlatıcı egzersizler yapılması teşvik edilmelidir. Uygun dinlenme aralarının verilmesi, çalışan rotasyonunun uygulamaya koyulması ve gün başında-sonunda germe gevşetme egzersizleri, kas 
iskelet sistemine yönelik riskleri azaltacak çok önemli iyileştirmeler olacaktır.

Diğer taraftan çalışanlara, uygun olmayan duruşların ve sonuçlarının neler olduğu verilen eğitimlerde anlatılmalı, gerekli ise eğitimler iş başlamadan önce tekrar hatırlatılmalıdır.

\section{Çıkar Çatışması}

Yazarlar tarafından herhangi bir çıkar çatışması beyan edilmemiştir.

\section{Kaynaklar}

Akay, D., Dağdeviren, M., Kurt, M. (2003). Çalışma Duruşlarının Ergonomik Analizi”. Gazi Üniversitesi Mühendislik Mimarlık Fakültesi Dergisi, 18(3): 73-84.

Atıcı, H., Gönen, D., Oral, A. (2015). Çalışanlarda Zorlanmaya Neden olan Duruşların Reba Yöntemi ile Ergonomik Analizi. Süleyman Demirel Üniversitesi Mühendislik Bilimleri ve Tasarım Dergisi 3(3):239-244, ÖS: Ergonomi2015, ISSN: 1308-6693

Aygün, İ., Çakmak, B., \& Alayunt, F. N. (2018). Narenciye Hasadının Ergonomik Açıdan İncelenmesi. Süleyman Demirel Üniversitesi Mühendislik Bilimleri ve Tasarım Dergisi, 6:312318.

Bilir, N. (2011). Meslek Hastalıkları Tanı, Tedavi Ve Korunma İlkeleri. Hacettepe Tıp Dergisi, 42(4): 142-157.

Das, B. Gangopadhyay, S. (2015). Prevalence Of Musculoskeletal Disorders And Physiological Stress Among Adult, Male Potato Cultivators Of West Bengal, India. Asia-Pac. J. Public Health, 27: 1669-1682.

Das, B., Ghosh, T., Gangopadhyay, S. (2013). Child Work in Agriculture In West Bengal, India: Assessment of Musculoskeletal Disorders And Occupational Health Problems. J. Occupation. Health, 55 (4): Erişim adresi: https://www.jstage.jst.go.jp/article/joh/advpub /0/advpub_12-0185-0A/_article/-char/ja/

Deros, B. M., Ali, M. H. Mohamad, D., Daruis, D.D.I. (2016). Ergonomic Risk Assessment On Oil Palm İndustry Workers. Iran. J. Public Health, 45, 44-51

Ekonomik Araştırmalar Şubesi (2021), Erişim Adresi: https://tim.org.tr/files/downloads/Ulke_Bilgi_N otlar\%C4\%B1/Zeytin\%20ve\%20Zeytinya $\%$ C $4 \%$ 9F\%C4\%B1\%20Hedef\%20Pazar $\% 20$ Bilgi $\% 20 \mathrm{~N}$ otu.pdf
Enez, K., Nalbantoğlu, S.S. (2015). Reba Yönteminin Ormancılık Faaliyetleri Açısından Değerlendirilmesi, Süleyman Demirel Üniversitesi Mühendislik Bilimleri ve Tasarım Dergisi 3(3), 127-131, ISSN: 1308-6693

Erdemir, F., Eldem C. (2020). Bir Döküm Atölyesindeki Çalışma Duruşlarının Dijital İnsan Modelleme Tabanlı REBA Yöntemi ile Ergonomik Analizi, Politeknik Dergisi, 23(2), 435-443

Eriş, H. Can, G.F., Fığlalı, N., (2014). Çalışma Duruşu Ve Kas-iskelet Sistemi Rahatsızlıkları. Erişim Adresi:

https://www.isgturkiye.com/konu/calismadurusu-ve-kas-iskelet-sistemi$\underline{\text { rahatsizliklari.1555/2014 }}$

Esen H., Fığlalı N. (2013). Çalışma Duruşu Analiz Yöntemleri Ve Çalışma Duruşunun Kas-İskelet Sistemi Rahatsızlıklarına Etkileri, SAÜ. Fen Bilimleri Dergisi. 17 (1),41-51.

Gutierrez-Hita, M., Galan-Gomez, M., Perez-Diaz, M., Ferre Callejon, J.A. (2020). An Overview of REBA Method Applications in the World. International Journal of Environmental Research and Public Health, Vol 17, Issue 8, 2635 Erişim Adresi: https://www.mdpi.com/1660-4601/17/8/2635

Hignett, S., McAtamney, L. (2000). Rapid Entire Body Assessment (REBA). Applied Ergonomics, 31, 201205.

İçağasıoğlu, A., Yumuşakhuylu, Y., Ketenci, A., Toraman, N.F., Maymak Karataş G., Kuru, Ö., Kirazlı, Y., Çapacı, K., Eriman, E. \& Haliloğlu, S. (2015). Burden Of Chronic Low Back Pain İn The Turkish Population. Turkish Journal of Physical Medicine and Rehabilitation, 61, 58-64

Kahya, E. (2020). Bir Metal Sanayi İşletmesinde Fiziksel Zorlanmaların Kas İskelet Sistemi Rahatsızlıklarına Etkisi, Endüstri Mühendisliği Dergisi, 31(2):148-158

Kaya, Ö. ve Akalp, G. (2017). İș Sağlığı ve Güvenliği Açısından Elle Taşıma İşlerinin Değerlendirilmesi (Tekstil ve Otomotiv Sektörü Örneği). "Ișs, Güç" Endüstri İlişkileri ve Insan Kaynakları Dergisi, 19 (2):75-90.ISSN: 2148-9874,

Kaya, Ö. (2015). Design of Work Place and Ergonomics in Garment Enterprises. Procedia Manufacturing 3, DOI: 10.1016/j.promfg.2015.07.921 Available online at www.sciencedirect.com p: 6437-6443.

Kaya, Ö. ve Özok, A. F. (2017). Tasarımda Antropometrinin Önemi. Süleyman Demirel Üniversitesi Mühendislik Bilimleri ve Tasarım Dergisi, Cilt 5, Özel Sayl, DOI: 10.21923/jesd.45182, e-ISSN: 1308-6693, s: 309316. 
Kır, İbrahim. (2015). Adana Ve Mersin Bölgesinde Seracılık Sektöründe Çalışanların Karşılaştığı Ergonomik Risklerin Değerlendirilmesi Çalışma ve Sosyal Güvenlik Bakanlığı \& Müdürlüğü, Erişim Adresi: https://ailevecalisma.gov.tr/media/1444/ibrahimki r.pdf

Inyang N., Al-Hussein, M, El-Rich, M, and Al-Jibouri S, (2012). Ergonomic Analysis and the Need for Its Integration for planning and assessing Management", 138:1370-1376.

Özel, E., Çetik, O., (2010). Mesleki Görevlerin Ergonomik Analizinde Kullanılan Araçlar ve Bir Uygulama Örneği. Dumlupınar üniversitesi Fen bilimleri Enstitüsü Dergisi, 22:41-56.

Pal, A. Dhara, P.C. (2018). Work Related Musculoskeletal Disorders and Postural Stress Of The Women Cultivators Engaged İn Uprooting Job Of Rice Cultivation. Indian J. Occup. Environ. Med. 2018, 22, 163-169. Erişim Adresi: https://www.ncbi.nlm.nih.gov/pmc/articles/PM C6309355/

Polat, O., Mutlu, Ö., Çakanel, H., Doğan, O., Özçetin E., Şen E., (2016). Bir Mobilya Fabrikasında Çalışan İşçilerin Çalışma Duruşlarının Reba Yöntemi İle Analizi. Mühendislik Bilimleri ve Tasarım Dergisi, 5,263-268, 2017 e-ISSN: 1308-6693

Riemer, R. Bechar, A. (2016). Investigation of Productivity Enhancement And Biomechanical Risks in Greenhouse Crops. Biosyst. Eng. 2016, 147, 39-50 Erişim Adresi: https://www.sciencedirect.com/science/article $\angle$ pii/S1537511015304475?casa_token=XX6zuT M8lHkAAAAA:P4enGBDxqNcHOvoEsgPoTc0mr7 sQGqy047QvnFWmbi1EdXFuzU1ixZM50JbERhf h9om70x8VSes

Rud, S. (2011). An Ergonomic Analysis Of Current Lifting Techniques in Height Restricted Cargo Bins At Company XYZ. The Graduate School University of Wisconsin-Stout.

Sa, F., Nascimento M.A., Melo A.C., Santos J.C. and Adissi P. J. (2006). Comparison of Methods Rula and Reba for Evaluation of Postural Stress in Odontological Services. 3rd International Conference on Production Research - Americas' Region.

Sakar E., Ünver H. (2011). Türkiye'de Zeytin Yetiştiriciliğinin Durumu Ve Ülkemizde Yapılan Bazı Seleksiyon Ve Adaptasyon Çalışmaları" HR.Ü.Z.F. Dergisi, 2011, 15(2): 19-25 J

Silver, K. Hoffman, K. Loury, S. Fethke, N.B. Liebman, A. Manz, N. Manock, S. Andino, A. Bradfield, M. Morrissette, D. (2014). Campus-community Partnership For Farmworkers' Health: Interventions For Tomato Workers İn
Tennessee. Prog. Community Health Partnersh. Res. Educ. Act. 8, 501-510. Erişim Adresi: https://muse.jhu.edu/article/575444/summary

Stanton N, Hedge A., Brookhuis K., Salas E., Hendrick $\mathrm{H}$, editors. "The Handbook Of Human Factors And Ergonomics Methods". Boca Raton, FL, USA: CRC Press

Waldemar K., William S. M. The Occupational Ergonomics Handbook. Fundamentals and Assessment Tools For Occupational Ergonomics". Second Edition:7-8. 